\title{
AS NOVAS CONFIGURAÇÕES DO MERCADO DE TRABALHO URBANO NO BRASIL: notas para discussão'
}

\author{
Angela Borges*
}

\begin{abstract}
O trabalho investiga os impactos das mudanças registradas entre 2002 e 2009 no mercado de trabalho urbano do Brasil sobre os trabalhadores, levando em conta a sua segmentação em grupos resultantes da interseção das dimensões de idade, gênero e escolaridade. Nele, faz-se uma breve análise das alterações observadas nesses sete anos no perfil sociodemográfico da população em idade de trabalhar para, em seguida, investigar os níveis de ocupação, de desocupação e de formalização dos diversos segmentos de trabalhadores definidos a partir dessas variáveis. Para tanto, foi construído e analisado um conjunto de indicadores, baseados em dados da PNAD, que dão conta da inserção no mercado de trabalho de homens e mulheres jovens, adultos e idosos segundo o nível de escolaridade e permitem visualizar as novas configurações do mercado de trabalho que emergem no ciclo expansivo da economia dos últimos sete anos.

PALAVRAS-CHAVE: mercado de trabalho; idade, sexo, escolaridade; formas de inserção.
\end{abstract}

As transformações no mercado de trabalho brasileiro da década de noventa expressam um contexto marcado por uma forte crise para os que vivem do trabalho, já amplamente conhecido: desemprego massivo e de longa duração, retração do emprego formal, flexibilização e precarização dos vínculos e aumento da informalidade. Os estudos desse período mostram que essa crise afetou, inclusive, os segmentos até então mais protegidos das incertezas inerentes ao vínculo empregatício (desemprego, perdas salariais e de benefícios, etc.): os servidores públicos e os empregados das grandes empresas públicas e privadas, além daqueles que, pelos seus atributos, estão menos expostos aos riscos do mercado de trabalho, como os homens adultos e os mais escolarizados.

\footnotetext{
* Socióloga. Doutora em Ciências Sociais. Profa ${ }^{\text {a do Mestrado }}$ em Políticas Sociais e Cidadania da UCSAL. Pesquisadora do Núcleo de Estudos do Trabalho da UCSal.

Campus da Garibaldi. Av. Anita Garibaldi, 2981. Cep: 40.231-902 - Rio Vermelho - Garibaldi. Salvador - Bahia Brasil.angelborges@uol.com.br

${ }^{1}$ Uma versão preliminar deste texto foi apresentada no XXVII Congresso ALAS, agosto/setembro de 2009 em Buenos
} Aires.
Nesse quadro desfavorável para os trabalhadores, foi possível, no entanto, identificar segmentos que arcaram com os maiores ônus: os trabalhadores dos segmentos mais profundamente reestruturados - como os operários da moderna indústria, grande parte deles definitivamente expulsos dos espaços mais valorizados do mercado de trabalho (Cardoso, 2000) e, de uma maneira geral, os trabalhadores que integram a chamada força de trabalho secundária (jovens e mulheres), em especial aqueles com baixa escolaridade e sem os diplomas mais elevados, para os quais tornou-se mais difícil o acesso a posto de trabalho socialmente protegido, quando não a qualquer posição no mercado de trabalho, jogando grande parte deles em situação de desemprego aberto ou oculto.

Nos anos 2000, mais especificamente a partir de 2004 (Pochmann, 2010, p.215), a economia brasileira volta a crescer como resultado da confluência de fatores internos e externos favoráveis e, diferentemente do observado na década anterior, a curva do emprego ou ocupação voltou a acompanhar a da produção, um movi- 
mento que, somado à recuperação dos rendimentos - em especial daqueles próximos ou vinculados ao salário mínimo -, iniciou um ciclo de expansão do consumo e da produção, com reflexos positivos sobre a capacidade de geração de novos postos de trabalho da economia, ainda que o aprofundamento da crise global, no último trimestre de 2008, tenha repercutido negativamente sobre a economia brasileira. ${ }^{2}$

Essa retomada do crescimento da economia brasileira na primeira década do século XXI não repete as tendências passadas: essa economia já é outra, o mercado de trabalho e as relações de trabalho foram profundamente transformados. Com o aumento acentuado do diferencial de poder entre empregados e empregadores, com a fragilização e desmobilização do movimento sindical, as relações de trabalho e as formas de contratação foram flexiprecarizadas ${ }^{3}$ e o debate sobre os trabalhadores e os seus direitos foi despolitizado e secundarizado, quando não retirado da cena pública.

Simultaneamente a essas transformações no plano da economia e da política, duas importantes mudanças sociodemográficas atuaram fortemente sobre a estrutura e a dinâmica do mercado de trabalho no Brasil na presente década. Uma delas, a transição demográfica, em estágio já bastante avançado, vem alterando rapidamente a composição do lado da oferta nesse mercado isto é, dos trabalhadores -, com a mudança do peso relativo dos grupos etários que compõem a

${ }^{2}$ Segundo Pochmann, os indicadores da economia brasileira mostraram que o conjunto de mudanças no cenário internacional trouxe para o Brasil uma "inegável ameaça à própria continuidade do ciclo positivo de resultados econômicos e sociais” (Pochmann, 2010, p. 215). Isso significa que a confluência de fatores que levou ao ciclo de expansão recente pode facilmente se dissipar e que o melhor desempenho da economia nacional e seu efeito positivo sobre o mercado de trabalho ainda não se assentam em bases sólidas.

${ }^{3}$ A expressão é inspirada em Bourdieu (1998) e em autores cujos estudos constatam os nexos causais entre as estratégias de flexibilização que integram os modelos de gestão influenciados pelo toyotismo - terceirização, jornada modulada, polivalência, individualização das relações de trabalho, dentre outras - e o processo de precarização no seu sentido mais amplo: dos vínculos, do posto de trabalho, da proteção social, dos mecanismos de representação, etc. Dentre outros, ver, por exemplo, os trabalhos de ThebaudMony e Druck,; (2007), Druck e Franco (2007); Linhar (2007). Ivo (2008). população em idade de trabalhar: redução do segmento mais jovem e aumento, em ritmos variados, das parcelas formadas por trabalhadores adultos e velhos. Por outro lado, mudanças sociodemográficas vêm repercutindo ainda, de outra forma, sobre o mercado de trabalho: a rápida redução no número médio de filhos por mulher e o tamanho médio das famílias contribuem para acelerar o processo de entrada das mulheres no mercado de trabalho e alterar o seu padrão de participação.

Outro fator de impacto sobre o mercado de trabalho diz respeito à elevação do nível de escolaridade dos ofertantes de trabalho, com a chegada à idade de trabalhar das gerações beneficiadas pela rápida expansão do sistema educacional de segundo e terceiro graus nas duas últimas décadas. Esses fatores articulados produziram condições diferenciais de inserção de trabalhadores, homens e mulheres, jovens, adultos e idosos, segundo o nível de escolaridade e permitem visualizar as novas configurações internas do mercado de trabalho que emergem no ciclo expansivo da economia.

Este texto discute essas novas configurações do mercado de trabalho urbano no Brasil, ressaltando os movimentos de diferenciação com base nos atributos sociodemográficos da idade, do sexo e da escolaridade. Para melhor visualizar os impactos do recente dinamismo da economia sobre o mercado de trabalho, tomou-se como referência o período entre 2002 e 2009. Ou seja, o ponto inicial (2002) é marcado por indicadores que exibem os efeitos negativos do ajuste neoliberal implementado a partir dos anos noventa, caracterizados por desregulamentação dos mercados, flexibilização do mercado de trabalho e desestruturação do Estado de bem-estar social (Marques, 1998); e o ponto final (2009) é um momento que incorpora os resultados positivos do primeiro ciclo de expansão pós-ajuste o qual, embora ainda muito recente e com possibilidades de desdobramentos ainda não consolidadas, já apresenta repercussões sobre o mercado de trabalho, cujo desenvolvimento e significado é importante que sejam examinados desde já. 
Para sustentar os argumentos aqui desenvolvidos, tomamos por base os dados da PNAD/ IBGE, considerando-se as variáveis de idade, escolaridade e sexo. Foram definidos três grandes grupos de idade, observando-se o ciclo de vida ativa e a composição da força de trabalho do "núcleo estruturado" do mercado de trabalho: (i) os Jovens (20 a 29 anos), em fase de inserção no mercado de trabalho e de transição escola-trabalho; (ii) os Adultos (30 a 49 anos), o hard core da força de trabalho, que apresentam as taxas de participação e de ocupação mais elevadas; e (iii) os Maduros ou Velhos (50 anos ou mais), trabalhadores que se encontram na fase da vida ativa em que se inicia a queda mais acentuada das taxas de atividade e, para a maioria, um momento de saída do núcleo da força de trabalho das empresas privadas, as quais, na ausência de proteções contra demissões imotivadas, desligam precocemente a maior parte dos seus empregados. Não é por outra razão que esse último grupo etário tem participação mais elevada no setor público, exatamente em função da perspectiva de carreira e de maior estabilidade no emprego.

A segunda dimensão, a da escolaridade, foi observada por meio de indicadores construídos para três faixas de anos de estudo, definidas em função da relevância dos diplomas obtidos no mercado de trabalho: até Ensino Médio Incompleto, Ensino Médio Completo ou Superior Incompleto e Superior Completo. Finalmente, para dar conta das mudanças e desigualdades de trabalhadores por sexo no mercado de trabalho, os indicadores foram calculados separadamente para homens e mulheres.

Como dito, os indicadores aqui analisados referem-se à média do mercado de trabalho urbano do Brasil, mas é importante pontuar, em um país marcado por profundas desigualdades inter e intrarregionais, essa média nacional sempre esconde importantes diferenças que não podem ser ignoradas. Trata-se de diferenças que

${ }^{4}$ Considera-se como "núcleo estruturado" o espaço do mercado de trabalho onde estão os empregos socialmente protegidos do setor público e dos empreendimentos privados. resultam, em parte, do tamanho e do perfil de cada economia e da sua posição nas divisões interregional e internacional do trabalho, e, portanto, do desenho da sua estrutura setorial e ocupacional, aspectos fundamentais para a determinação da capacidade de incorporação de trabalhadores de uma economia e da qualidade dessa incorporação.

Desse modo, assim como as características de cada economia em particular foram decisivas na configuração dos impactos da reestruturação produtiva dos anos noventa sobre o mercado de trabalho e sobre os trabalhadores, ${ }^{5}$ elas também influenciam o perfil assumido pela recuperação desses mercados de trabalho, no recente período de expansão. Em que pese o fato de este artigo não se desdobrar em termos de indicadores de desigualdades regionais, deve-se ter presente que os processos aqui analisados embutem singularidades e particularidades regionais e que, portanto, eles não se manifestam de forma homogênea em todo o país. Pelo contrário, dadas as profundas desigualdades e heterogeneidades regionais existentes no país, certas características são mais marcantes em alguns mercados do que em outros, e os indicadores podem divergir bastante entre mercados de trabalho particulares, apontando, muitas vezes, tendências opostas entre eles.

\section{A RECUPERAÇÃO DO MERCADO DE TRA- BALHO BRASILEIRO: principais traços}

De forma a dar significado aos movimentos específicos do mercado de trabalho brasileiro a partir dos indicadores por idade, escolaridade e sexo, apresenta-se a seguir um breve panorama das principais transformações do mercado de trabalho urbano do Brasil no período em estudo, de 2002 a 2009.

\footnotetext{
${ }^{5}$ Em vários outros textos da autora, foram discutidas as diferenças regionais, em especial entre as regiões metropolitanas, para dar conta do impacto da reestruturacão produtiva sobre os respectivos mercados de trabalho (Cf. Borges, 2003) e das suas consequências em termos de
} vulnerabilidade social (Cf. Borges, 2006). 
Tomando por base dados dos anos $2000 \mathrm{e}$, em especial, a partir de 2004, os indicadores do mercado de trabalho começaram a registrar melhoras significativas, como resultado da recuperação do nível de atividade; da mudança no padrão de atuação do Estado - no que se refere à fiscalização do cumprimento das legislações trabalhista e previdenciária e à arrecadação a elas vinculada; à atuação do poder judiciário e do Ministério Público do Trabalho - além dos efeitos positivos de valorização do salário mínimo e de popularização do crédito ao consumidor, das políticas de transferência de renda e de combate à pobreza sobre algumas atividades. As consequências dessas mudanças fizeram-se sentir em todo o país, mesmo que de forma de desigual.

Entre 2002 e 2009, os grandes números mostram que o mercado de trabalho urbano ${ }^{6}$ apresentou um comportamento radicalmente distinto do observado na década anterior sob vários aspectos: o número de ocupados cresceu mais do que a população economicamente ativa (2,6\% a.a. e $2,4 \%$ a.a., respectivamente), mas esse crescimento não foi homogêneo em todo o país. Assim, nos mercados de trabalho metropolitanos, o ritmo de crescimento da ocupação variou bastante, sendo o mais elevado (4,4\% a.a.) o da Região Metropolitana de Salvador, que ostenta, historicamente, a maior taxa de desemprego no cenário metropolitano, alternando com Recife essa posição (Borges, 2003, p.105). e os menores (cerca de 1,5\% a.a.) os de Recife e de Porto Alegre.

O aumento da ocupação provocou uma expressiva redução das taxas de desemprego aberto, de 10,6\% para 9,3\% no agregado do Brasil urbano, levando os mais otimistas a falarem de "pleno emprego" no final do período considerado, tomando como referência o comportamento dos mercados de trabalho de algumas regiões

${ }^{6}$ Neste panorama, considera-se toda a população com 10 anos ou mais, diferentemente da análise que se fará a seguir, que considera a população de 20 anos ou mais, não contemplando, portanto, os segmentos das crianças, dos adolescentes e dos jovens de 18 e 19 anos, cuja participação no mercado de trabalho exige a consideração de fatores específicos, que ultrapassam os limites de um artigo. metropolitanas. No entanto, mesmo com essa expansão da ocupação, ainda ocorreu um acréscimo de cerca de 313 mil trabalhadores ao estoque de desempregados, o qual alcançava o patamar de 7,9 milhões de trabalhadores no final 2009, segundo a PNAD, ${ }^{7}$ tendência coerente com o novo padrão de desenvolvimento do capitalismo, que tem no desemprego estrutural um dos seus principais componentes (Mészaros, 2006),

Quanto às formas de inserção dos ocupados, a proporção de assalariados ${ }^{8}$ passou de $59,9 \%$ para $63,5 \%$ do conjunto dos ocupados nas áreas urbanas, e o número de empregados com carteira assinada cresceu a uma taxa de $4,8 \%$ a.a., elevando de $33,0 \%$ para $39,3 \%$ o percentual de ocupados nessa posição. Como, nesse período, também o emprego público cresceu a um ritmo superior ao da ocupação total (cerca de 3,6\% a.a.), em 2009, a proporção de trabalhadores com emprego socialmente protegido era de $47,4 \%$. Esse é o indicador que tem sido mais ressaltado por analistas do comportamento do mercado de trabalho nesse período, por duas razões. A primeira, por interromper o enxugamento do núcleo estruturado do mercado de trabalho ocorrido nos anos noventa, ao menos até a crise do final de 2008. E a segunda, por contrariar as expectativas - sobretudo dos analistas neoliberais - de que a completa desregulamentação do mer-

7 Já os mercados de trabalho metropolitanos registraram redução absoluta nos respectivos estoques de desempregados, sinalizando para uma concentração de novos postos de trabalho nesses espaços mais dinâmicos da economia brasileira. De qualquer modo, em 2009, 3,1 milhões de trabalhadores permaneciam em situação de desemprego nessas regióes, o equivalente a cerca de $40 \%$ do estoque de desempregados do Brasil urbano.

${ }^{8}$ São considerados: os empregados com carteira; os funcionários públicos e militares e os empregados sem carteira. Esse recorte deixa de fora os empregados submetidos a formas de contratação que buscam descaracterizar o vínculo empregatício, a exemplo das falsas cooperativas de trabalho e da prestação individual de serviço por trabalhadores que constituem pessoa jurídica por solicitação do empregador. Essas são formas que proliferaram na reestruturação dos anos noventa e seguem sendo amplamente utilizadas em alguns setores, mas ainda não são captadas pelas pesquisas domiciliares que baseiam as análises do mercado de trabalho. Além disso, contra todas as evidências, argumentouse que a regulação das relações capital x trabalho no Brasil impunha uma rigidez à contratação e ao uso da força de trabalho, a qual se configurava inadequada a uma realidade marcada pela instabilidade dos mercados, pela competição acirrada centrada nos custos e pela incerteza que tudo isto gera" (Borges, 2003, p.94). 
cado de trabalho seria uma tendência inexorável e uma condição necessária ao bom desempenho da economia no atual estágio do capitalismo. ${ }^{9}$

Apesar da recuperação do chamado "emprego formal", em 2009, mais da metade dos ocupados residentes em áreas urbanas ainda ocupava postos de trabalho socialmente desprotegidos, o que traduz os limites da atual recuperação de empregos do núcleo duro de mercado de trabalho.

Essa criação de empregos com carteira assinada não foi uniforme em todos os mercados de trabalho. O da Região Metropolitana de Salvador, por exemplo, apresentou um incremento de empregos formais dos mais elevados (53,3\%), porém permanece, nessa região, o crescimento percentual de empregados sem carteira $(24 \%$ entre 2002 e 2009), sinalizando para a persistência da precariedade como traço estrutural desse mercado. Tomando por referência comparativa o mercado de trabalho na R.M. de São Paulo, o mais estruturado do país, o incremento dos empregos com carteira nessa região foi mais modesto $(35,5 \%)$, mas veio acompanhado da redução absoluta dos empregos sem carteira, sinalizando um movimento de estruturação mais consistente que o observado na RMS.

Analisando as informações por setor de atividade e posição na ocupação, vê-se que, no conjunto do Brasil urbano, quase todas as posições registraram crescimento absoluto, com exceção daquelas residuais nos mercados de trabalho urbanos: as dos "não-remunerados" e dos trabalha-

${ }^{9}$ Segundo Borges "A desregulamentação do mercado de trabalho foi justificada por uma suposta inadequação aos novos tempos da regulação das relações de trabalho vigente no país. Afirmou-se que toda a legislação em vigor, assim como os demais componentes do arcabouço institucional responsável por essa regulação, corresponderia a uma realidade já ultrapassada, e que a sua manutenção estaria colocando obstáculos à competitividade da economia brasileira e, logo, à geração de novos postos de trabalho. Isso ocorreria porque os direitos trabalhistas vigentes responderiam por boa parte do Custo Brasil, na medida em que os encargos sociais que embutem na folha de pagamento acabariam por colocar num patamar pouco competitivo os custos da mão de obra no país.

Além disso, contra todas as evidências, argumentou-se que a regulação das relações capital $x$ trabalho no Brasil impunha uma rigidez à contratação e ao uso da força de trabalho, a qual se configurava inadequada a uma realidade marcada pela instabilidade dos mercados, pela competição acirrada centrada nos custos e pela incerteza que tudo isto gera” (Borges, 2003, p.94). dores em “atividades ligadas à subsistência”. Dentre as seis posições que mais cresceram, quatro foram de "emprego com carteira" no Comércio e Reparações, Indústria de Transformação, Outras Atividades e na Construção Civil. As duas outras correspondem a empregos de funcionário público na administração pública e nos serviços de educação, saúde e serviços sociais.

Apesar de esses números sinalizarem para a criação de postos de trabalho de maior qualidade, a distribuição dos ocupados por classes de rendimento em salário mínimo mostra que, no saldo do período, apenas as classes de até 5 salários mínimos registraram resultado positivo, observando-se a redução absoluta do número de ocupados com rendimentos acima desse patamar. Em termos relativos, apenas as classes de "Mais de $1 / 2$ a 1 S.M." e de "Mais de 1 a 2 S.M." elevaram a sua participação no estoque de ocupados.

Essa constatação deixa evidente a nova configuração do mercado de trabalho pósreestruturação: os baixos salários são a base sobre a qual se ergue a retomada do crescimento, apesar da crescente escolaridade dos trabalhadores, como será analisado a seguir. Obviamente, desagregando os dados por Unidade da Federação e por Região Metropolitana, esse indicador mostrará um quadro bem mais complexo, com a distribuição desigual dos postos de trabalho mais bem remunerados, os quais tendem a se concentrar nos espaços e regiões que também concentram as atividades que agregam mais valor e com elevada produtividade, a exemplo de São Paulo.

\section{AS MUDANÇAS DO MERCADO DE TRABA- LHO BRASILEIRO DOS ANOS 2000, SEGUN- DO AS DIMENSÕES DE IDADE, SEXO E ESCOLARIDADE}

Analisando inicialmente as tendências observadas segundo os grupos de idade da população com 20 anos ou mais, constata-se, entre 2002 e 2009, a continuidade da redução da participação relativa dos jovens (de $28,3 \%$ para 
25,9\% da população com 20 anos ou mais) e, em menor medida, dos adultos (de 44,2\% para $42,4 \%$ ), como resultado de mudanças demográficas - chegada à juventude das primeiras gerações nascidas num contexto de queda da fecundidade, emigração dos mais jovens - e, simultaneamente, aumento da participação dos maduros ou velhos, de $27,7 \%$ para $31,7 \%$, traduzindo o envelhecimento da população. Os jovens e adultos também reduziram a sua participação nos agregados da População Economicamente Ativa (PEA) e dos Ocupados, apesar da elevação das taxas de atividade específicas por sexo e idade e do comportamento positivo da ocupação.

Para a elevação do peso dos maduros ou velhos na PEA e entre os Ocupados, é possível que, além do componente demográfico, também estejam contribuindo o adiamento da entrada na inatividade em decorrência do aumento da idade mínima para aposentadoria, além de mudanças nas estratégias familiares de formação da renda, induzidas tanto pela contenção dos salários mais elevados como pela necessidade de compensar a redução da participação dos mais jovens na composição dessa renda (em função do desemprego e da precariedade dos postos de trabalho que conseguem ocupar).

A taxa de atividade subiu praticamente para todos os grupos de idade - a única exceção são os maduros ou velhos do sexo masculino, cuja taxa apresentou leve queda - e esse aumento foi, sobretudo, feminino, atingindo as mulheres dos três grupos etários aqui referidos. As taxas masculinas mantiveram-se estáveis, registrando pequenos aumentos entre os jovens e adultos, mais uma evidência do papel relevante desempenhado pelas mulheres nas estratégias familiares de adequação a um mercado de trabalho em rápida transformação.

Quanto à ocupação, o número de Ocupados cresceu em termos absolutos para a maior parte dos 18 grupos resultantes do cruzamento das variáveis idade, sexo e escolaridade, sendo os grupos formados pelos jovens de ambos os sexos com escolaridade inferior ao curso univer- sitário os únicos a registrarem decréscimo absoluto no período, em consequência tanto da redução do contingente com escolaridade inferior ao Ensino Médio como das dificuldades de inserção do segmento juvenil no mercado de trabalho. Já a Taxa de Ocupação específica por idade, sexo e escolaridade, calculada com relação à PIA (Ocupados /População no grupo etário) subiu para quase todos os grupos, inclusive para os jovens. As exceções foram as mulheres adultas com escolaridade superior, que apresentaram leve decréscimo em suas Taxas de Ocupação, sugerindo dificuldades de inserção para esse segmento.

Como visto, esse crescimento da ocupação levou à queda expressiva das taxas de desemprego, mas não conseguiu reduzir, significativamente, o contingente de desempregados. Os dados mais desagregados para a população de 20 anos ou mais revelam a persistência de taxas de desemprego aberto ainda elevadas para alguns segmentos de trabalhadores - os jovens e as mulheres -, evidenciando a permanência de condições adversas no mercado de trabalho, apesar da elevação do nível de atividade econômica e dos ganhos de escolaridade desses dois segmentos.

As taxas de desemprego são bastante sensíveis à idade, sendo mais elevadas nos primeiros anos da vida ativa, tendendo a cair rapidamente após a juventude (Borges, 2008b). Desse modo, mesmo com a redução do desemprego ocorrida entre 2002 e 2009, nesse último ano as taxas juvenis ainda equivaliam a aproximadamente o dobro das taxas dos adultos e a mais do triplo das taxas dos maduros ou velhos, tanto para homens como para mulheres. Como resultado, a participação juvenil no estoque de desempregados continuou relativamente significativa e elevada em relação à sua proporção na ocupação e na PEA: os jovens entre 20 e 29 anos representavam, em 2009, apenas cerca de 25,9\% da população com 20 anos ou mais, 30\% da PEA e $28,2 \%$ dos ocupados, porém constituíam mais da metade (50,9\%) dos desempregados residentes nas áreas urbanas do país.

Em trabalho anterior (Borges, 2008a), já 
era constatada essa sobrerrepresentação dos jovens no contingente de desempregados, que não deve ser interpretada como indicador de exclusão desse segmento do mercado de trabalho, como é comum em análises mais apressadas e nas justificativas de programas públicos e privados orientados para esse segmento. Isso porque eles estão igualmente sobrerrepresentados no estoque de Ocupados e, como será mostrado, também no estoque de Empregados, indicando a importância desses trabalhadores para o capital.

Finalmente, mesmo apresentando taxas de desemprego muito mais baixas do que os jovens, os dois outros grupos etários não estão livres do risco do desemprego. Em 2009, a taxa média de desemprego aberto dos adultos era de 6,2\%, (8,5\% para as mulheres), patamar ainda elevado, mesmo para o padrão brasileiro, sobretudo quando se considera o papel de provedor ou coprovedor do núcleo familiar assumido por trabalhadores e trabalhadoras nessa fase da vida e os elevados níveis de desemprego por desalento e de inserção precária, que penalizam mais as mulheres e os velhos. Com esse nível de desemprego, no final do período estudado, depois de alguns anos de expansão da atividade econômica, cerca de $40 \%$ dos desempregados residentes nas áreas urbanas tinha entre 30 e 49 anos. Observe-se ainda que $60,4 \%$ deles era constituído por mulheres e nada menos do que $1 / 4$ do estoque de desempregados era formado por mulheres adultas.

Quanto às formas de inserção dos Ocupados no mercado de trabalho urbano, no período de recuperação (2002 - 2009), observa-se uma elevação superior a três pontos percentuais na Taxa de Assalariamento (Empregados/Ocupados): de $56,7 \%$ para $60,4 \%$. Esse indicador subiu para todos os grupos etários e para ambos os sexos, tornando patente a manutenção da centralidade do contrato de trabalho, a forma tipicamente capitalista de trabalhar, após quase duas décadas de reestruturação da economia brasileira, contrariando grande parte das análises dos anos noventa e as teses neoliberais, as quais, antevendo uma era de crescimento sem empregos e de gan- hos de liberdade do capital com relação à sua histórica e estrutural dependência do trabalho, constituíram-se em importante arma ideológica para a desmobilização e desmoralização dos trabalhadores (Bourdieu, 1998b)

Essa centralidade do assalariamento como forma de incorporação da força de trabalho aos processos produtivos é mais marcante entre os jovens - a Taxa de Assalariamento desse grupo etário saltou de 69,9\% para 75,9\% entre 2002 e 2009 -, reafirmando que o emprego se mantém como a principal porta de entrada das novas gerações de trabalhadores no mercado de trabalho (Borges, 2008b). Note-se, porém, que a importância do emprego cai com o aumento da idade (em 2009, eram empregados 75,9\% dos Jovens, $59,5 \%$ dos Adultos e apenas 41,7\% dos maduros adultos) porque, como dito, no setor privado os trabalhadores são precocemente dispensados pelas empresas, mas também porque, num mercado de trabalho pouco estruturado, onde são reproduzidas continuamente as mais variadas formas de autoemprego e de pequenos negócios e onde a precariedade do emprego, os baixos salários e a quase ausência de chances de carreira são vivenciados pela maior parte dos que são empregados, a procura de alternativas fora do assalariamento - ou, o sonho da autonomia - está sempre presente e elas são buscadas não apenas pelos desempregados, mas também por uma parcela - sempre minoritária de trabalhadores que dispõem dos recursos materiais, de qualificação e relacionais necessários à sobrevivência fora de um emprego nos mercados de trabalho urbanos.

A crescente importância do emprego como forma de inserção no ciclo de expansão que se inicia em 2004 vem acompanhada também da expansão dos vínculos socialmente protegidos, resultado da geração de novos postos de trabalho no setor público e de contratos de trabalho formais no setor privado.

No universo da população com 20 anos ou mais, a Taxa de Formalização (empregados com carteira, militares e funcionários públicos / ocupados) deu um salto de $41,1 \%$ para $49,0 \%$ 
entre 2002 e 2009. Essa crescente formalização dos vínculos nos mercados de trabalho urbanos do Brasil alcançou trabalhadores dos três grupos etários, de ambos os sexos e de todos os níveis de escolaridade. Porém grande parte dos novos empregos formais gerados corresponde a postos de trabalho de baixa qualidade e mal remunerados. No período, foram gerados, nos mercados de trabalho urbanos, cerca de $8 \mathrm{mi}$ lhões de empregos com carteira assinada (CLT) ${ }^{10}$ e, desses, cerca de 1/4 pagava no máximo um salário mínimo e 80\% entre um e dois mínimos, registrando-se saldo negativo nas faixas salariais acima de cinco salários mínimos.

Simultaneamente, também contrariando expectativas e tendências anunciadas no final do século XX, no cômputo geral do Brasil urbano, registrou-se uma redução de $21,3 \%$ para $19,5 \%$ na participação dos trabalhadores por conta própria no conjunto dos Ocupados e também, de forma generalizada, para todos os segmentos de trabalhadores, apesar da continuidade do desemprego e dos baixos salários pagos pelos novos postos de trabalho. A quase estagnação do peso relativo dessa posição na ocupação no estoque de ocupados em seu patamar histórico contraria as formulações que apostavam no "empreendedorismo"11 dos trabalhadores como suposta tendência virtuosa ou como única alternativa à escassez de postos de trabalho assalariados, protegidos ou não. Embora seja evidente que, em alguns setores e regiões, exista espaço para uma expansão de postos de trabalho autônomos mais bem remunerados do que a maior parte das opções de inserção como assalariado - sobretudo quando acoplados a processos produtivos mais modernos comandados pelo capital -, tais oportunidades são sempre limitadas comparativamente ao número de trabalhadores nessa posição, que assim parece manter-se como espaço predominantemente precário e de invenção de mecanismos de sobrevivên-

${ }^{10}$ Dados relativos ao conjunto da população em idade ativa (10 anos ou mais).

${ }^{11}$ Aqui utilizado no sentido Shumpeteriano, como pessoa com criatividade e capacidade de vencer na vida mediante a mobilização de recursos e a inovação. cia por aqueles que não têm um emprego. O contraste entre Salvador e São Paulo - respectivamente um dos mais pobres e precários e o mais rico e mais estruturado mercado de trabalho metropolitano - parece ilustrar tanto essa vocação do "contaproprismo" quanto a sua heterogeneidade. Enquanto em Salvador, ${ }^{12}$ o percentual de ocupados por conta própria cresceu $24,2 \%$, na Região Metropolitana de São Paulo, onde estão a maior concentração de riqueza e o maior mercado consumidor do país - portanto, o espaço mais propício ao desenvolvimento do empreendedorismo - os ocupados por conta própria registram um incremento de apenas 3\% no período estudado, enquanto o incremento dos empregados alcançou 21,7\%.

Levando agora o foco da análise para as desigualdades entre os sexos e aquelas relativas aos níveis de escolaridade, observa-se que, entre 2002 e 2009, as mulheres, que são majoritárias na população urbana com mais de 20 anos, ampliaram a sua participação em todos os grandes agregados do mercado de trabalho urbano do Brasil, independentemente do nível de escolaridade alcançado. Apesar disso, elas ainda representavam menos de $50 \%$ em quase todos eles: passaram de $43,5 \%$ para 45\% na PEA; de 42,4\% para 43,7\% dos Ocupados; de 39,2\% para 40,7\% dos Empregados e de 39,8\% para 40,7\% dos Empregados Formais. O único agregado em que elas são majoritárias e ainda ampliaram a sua participação foi o dos Desempregados, confirmando a sua posição de desvantagem no mercado de trabalho, mas, também, a incapacidade de esse mercado incorporar o crescente número de mulheres que deseja trabalhar e que, cada vez mais frequentemente, têm o trabalho remunerado como a sua principal atividade. As taxas de desemprego femininas são substancialmente mais elevadas do que as masculinas em todas as idades, mas, principalmente, nas idades mais produtivas - entre os jovens e entre os adultos entre 30 e 49 anos - quando chegam a alcançar o dobro das taxas masculinas.

As mulheres também melhoraram a quali-

${ }^{12}$ Os dados relativos às Regiões Metropolitanas referem-se sempre à população com 10 anos ou mais. 
dade da sua inserção com o aumento da parcela com emprego formalizado, mas, ainda assim, a proporção das que estão nesse espaço menos desprotegido do mercado de trabalho é significativamente inferior à dos homens - 44,0\% e 50,5\%, respectivamente - e uma parcela expressiva delas continua ocupando o espaço do trabalho doméstico, que ainda representava, isoladamente, $18 \%$ da ocupação feminina nas áreas urbanas do país.

A análise dos indicadores relativos à escolaridade toma como medida de avaliação das mudanças nos anos 2000 a variável "Anos de Estudo", uma proxy imperfeita da qualificação dos trabalhadores e relevante na segmentação do mercado de trabalho e na determinação das chances e da forma de inserção dos trabalhadores, respondendo por algumas das mudanças mais marcantes do período. A ampliação - desde os anos 80 e em especial a partir dos anos 90 - do acesso à escola e a níveis de ensino cada vez mais elevados tem reflexos importantes sobre o perfil da oferta de trabalho e sobre a composição dos Ocupados e dos Desocupados.

Dois aspectos paradoxais chamam a atenção no que tange à escolaridade: de um lado, a rápida ampliação da oferta de vagas nos níveis Médio e Superior criou um gap geracional de escolaridade na força de trabalho; de outro lado, a persistência de grandes contingentes de pessoas com 20 anos ou mais em um baixo patamar de escolaridade, apesar dessa expansão, constitui-se fator limitador de acesso ao mercado de trabalho em postos mais qualificados.

Assim, em 2009, nada menos do que $56,0 \%$ da população com 20 anos ou mais, residente nas áreas urbanas do país, não superavam o patamar de escolaridade equivalente ao curso Médio Incompleto. Como a maior parte dessas pessoas já deixou o sistema educacional e dificilmente retornará a ele espontaneamente, concluise que, sem um investimento decisivo em políticas eficazes de educação de adultos e de garantia da permanência na escola das crianças, adolescentes e jovens, o Brasil levará para as próximas décadas uma força de trabalho com baixíssima escolaridade, se tomados como parâmetros os padrões dos países desenvolvidos - e, até mesmo, de países periféricos, como a Coreia do Sul - e as exigências das empresas que, já há algum tempo, vêm colocando o diploma do ensino médio como pré-requisito para contratação.

Quanto à velocidade e intensidade das mudanças na escolaridade, caiu de $67,3 \%$ em 2002 para 56,0\% em 2009 o percentual da população com 20 anos ou mais que não tinha o diploma do Ensino Médio e, entre os jovens, os principais beneficiados pela expansão tardia do sistema público de ensino brasileiro nos níveis médio e superior, essa queda foi de significativos 18 pontos percentuais em apenas sete anos (de $56,3 \%$ para $38,1 \%$ ). Ao mesmo tempo, os contingentes com diploma do Ensino Médio, cursando ou não a universidade, aumentaram de $25,2 \%$ para $33,3 \%$ do conjunto da população estudada, mas, entre os que tinham entre 20 e 29 anos, esse salto foi de $38,4 \%$ para $52,5 \%$, ultrapassando, portanto, o contingente sem diploma do Ensino Médio. Embora com percentuais bem menos expressivos, também aumentaram as proporções dos que concluíram ensino universitário (de 5,3\% para 9,4\%, entre os jovens). Tais proporções devem aumentar significativamente nos próximos anos, com a titulação dos numerosos contingentes de egressos de escolas públicas beneficiados pelos programas de cotas e de bolsas em instituições privadas. O gap geracional aparece claramente quando comparamos as proporções representadas pelos que tinham diploma do Ensino Médio ou mais em 2009, nos três grupos etários considerados: $61,9 \%$ dos jovens; $46,9 \%$ dos adultos e apenas $25,5 \%$ dos maduros ou velhos.

As consequências dessas mudanças sobre as chances de inserção nos mercados de trabalho urbanos do país são evidentes: cai, em todos os grupos etários e para ambos os sexos, a proporção de Ocupados sem diploma do Ensino Médio, um resultado combinado das mudanças na escolaridade da população e do caráter cada vez mais seletivo do mercado de trabalho. 
A consideração simultânea da escolaridade com a idade e o sexo mostra tanto a importância da escolaridade, mas também os seus limites. Como dito, relativamente ao seu peso na PEA os jovens entre 20 e 29 anos estão sobrerrepresentados no universo dos desempregados, independentemente da escolaridade alcançada, mas o fenômeno é mais marcante para os que não têm o diploma do Ensino Médio (55,8\% dos jovens desempregados) e para os que alcançaram esse grau de ensino e continuaram os estudos - grupo que inclui os estudantes universitários -, os quais representam nada menos que $40,9 \%$ dos jovens em situação de desemprego, em 2009. Além disso, a taxa de desemprego juvenil se mantém no mesmo patamar (entre 13\% e 14\% em 2009) nas duas primeiras classes de anos de estudo, o que sugere que, para os jovens, as chances de inserção aumentam apenas após a obtenção do diploma universitário, embora, mesmo entre aqueles que o possuem, a taxa de desemprego fosse de 7,5\%, em 2009.

Da mesma forma, para os ocupados jovens, esse diploma não se constitui em garantia de uma inserção compatível com as expectativas dos que o conquistaram, como se depreende do perfil dos postos de trabalho criados no período em estudo.

Já entre os Adultos e os Maduros/Velhos ocorre o contrário: vis a vis o seu peso na PEA, os menos escolarizados estão sub-representados entre os desempregados, o que certamente traduz a maior pressão deles sobre o mercado de trabalho e a sua aceitação de qualquer tipo de inserção; mas também pode estar sugerir que, em muitos espaços, a variável idade (também proxy de experiência/qualificação) tem sido mais relevante para assegurar um posto de trabalho do que os diplomas, à exceção do diploma universitário, o único cuja posse (por enquanto) ainda provoca uma inflexão significativa na taxa de desemprego.

Assim, em 2009, o grupo com menor escolaridade (até Ensino Médio incompleto) representava $57,7 \%$ da PEA com 20 anos ou mais e peso um pouco menor, 52,6\% dos desempregados nas áreas urbanas do Brasil. Enquanto isso, aqueles que haviam concluído esse grau de ensino e ainda não tinham o diploma do ensino superior correspondiam a 36,9\% da PEA, mas representavam $41,6 \%$ dos desempregados, confirmando as conclusões de Dedecca (2006), de que, sem uma melhoria significativa do mercado de trabalho o que está relacionado com o modelo de desenvolvimento seguido pelo país -, a elevação da escolaridade da população pode não resultar em maior número de ocupados, mas na elevação da escolaridade dos desempregados: no Brasil Urbano, em 2009, 51,1\% dos desempregados tinham, pelo menos, o diploma do Ensino Médio.

Note-se, ainda, que os diplomas têm mais relevância no núcleo do mercado de trabalho urbano. Nele, tomando-se o ano de 2009 como referência, vê-se que, para os três grupos etários, os empregados com menor escolaridade estão subrepresentados comparativamente ao seu peso na PEA, fenômeno que é mais frequente entre as mulheres. Além disso, a Taxa de Formalização, embora tenha aumentado em todas as faixas de escolaridade, dá um salto entre os que não possuem $(35,1 \%)$ e os que possuem $(61,1 \%)$ o diploma do Ensino Médio, evidenciando a importância atribuída a esse diploma pelos empregadores, sobretudo no caso da contratação de mulheres.

Essa importância é determinada tanto como estratégia de redução dos custos da seleção - restringindo o universo menor de candidatos -, como pelas necessidades concretas dos processos produtivos, sensivelmente transformados nos últimos 30 anos e em permanente mutação. São mudanças que demandam novas competências dos trabalhadores, mas também tornam a sobrequalificação uma variável fundamental para o bom desempenho do sistema produtivo, por dotá-lo de reservas de capacidade indispensáveis para enfrentar perturbações nos processos produtivos, para facilitar e reduzir os custos das mudanças tecnológicas e gerenciais e, sobretudo, para potencializar a flexibilização dos processos produtivos com trabalhadores dotados das 
competências mínimas para a polivalência.

Porém a redução da proporção de trabalhadores do núcleo com salários mais elevados e a permanente insegurança no emprego ${ }^{13}$ deixam claro que a valorização dos certificados do sistema educacional pelas empresas não tem assegurado aos contratados uma inserção efetivamente protegida. Constata-se, então, a fragilidade das teses recorrentes a partir dos anos noventa, que identificam, na baixa escolaridade e (ou) baixa qualificação dos trabalhadores, a determinação das dificuldades encontradas pelos desempregados e pelos desalentados. A adoção desse argumento, em última instância, traz implícita uma noção de culpabilização dos trabalhadores pelas suas dificuldades no mercado de trabalho, orienta boa parte da política pública de emprego e da política educacional, estimula os empreendimentos educacionais e tira do foco do debate o modelo de desenvolvimento, as contradições inerentes ao capitalismo e a sua crise, da qual o desemprego estrutural e a precarização do trabalho - inclusive dos trabalhadores mais escolarizados - são elementos centrais.

A seguir, procura-se extrair alguns significados dos indicadores analisados e levantar algumas hipóteses sobre a nova conformação da relação entre capital e trabalho no Brasil urbano.

\section{CONSIDERAÇÕES FINAIS}

A análise precedente parece nos levar a algumas considerações conclusivas. Em primeiro lugar, ela revela que a idade, o sexo e o nível de escolaridade são variáveis relevantes na determinação das chances de os trabalhadores ocuparem um posto de trabalho e da qualidade desse posto. Por outro lado, a intersecção entre essas variáveis revela um quadro complexo, permeado por fatores extraeconômicos - mudanças demográficas e culturais, preconceitos de toda ordem, regulação

${ }^{13}$ Entre 2002 e 2009, cresceu de 35,5\% para 36,8\% o percentual de empregados com carteira assinada e com menos de dois anos no emprego. do Estado etc. -, cuja compreensão exige um maior aprofundamento da análise, com a consideração de outras dimensões inerentes à estruturação desses mercados, como o setor de atividade e a ocupação, mas também informações qualitativas e quantitativas sobre as formas de inserção e condições de trabalho.

Mesmo sem esse aprofundamento, é possível afirmar que, tal como evidenciado na crise que se abateu sobre o mercado de trabalho brasileiro nos anos noventa, também na fase de recuperação o mercado de trabalho urbano no Brasil não tem sido capaz de acolher integralmente os segmentos de trabalhadores "jovens" e das "mulheres", que permanecem como os dois agregados mais expostos aos riscos desse mercado.

No caso dos jovens, isso acontece mesmo com a redução do ritmo de crescimento desse grupo etário, confirmando que os problemas detectados na relação jovem versus trabalho, nos anos noventa, não decorreram da rápida expansão desse segmento (a onda jovem) e da pressão que ele exerce sobre o mercado de trabalho. Do mesmo modo, no caso das mulheres, as dificuldades de inserção persistem, apesar de elas já apresentarem um padrão de participação semelhante ao dos homens e uma escolaridade média superior à deles.

A evolução das taxas de desemprego e dos contingentes de desempregados confirma o caráter estrutural desse fenômeno. Mesmo num ciclo de expansão do emprego, largos contingentes de trabalhadores não conseguem um posto de trabalho ou vivenciam a experiência do desemprego recorrente. Tal situação mantém a luta contra o desemprego na pauta dos que defendem os direitos dos trabalhadores e como prioritária para o desenho das políticas públicas voltadas para o mercado de trabalho.

Em segundo lugar, a análise precedente mostrou também que, nos anos 2000, o processo de desestruturação do núcleo do mercado de trabalho por meio do desassalariamento (redução do percentual de ocupados que têm emprego) e da destruição de postos de trabalho social- 
mente protegidos, marcante os anos noventa, foi interrompido, ou no mínimo, teve a sua intensidade bastante reduzida, muito embora a desregulamentação das relações de trabalho (em especial a flexibilização dos contratos e a criação de novos tipos de contrato ditos atípicos), levada a cabo de forma metódica no governo de Cardoso, não tenha sido revista, e as mudanças na legislação, necessárias para colocar limites ao processo de terceirização, um dos principais mecanismos de precarização das relações de trabalho e dos postos de trabalho, não tenham sido encaminhadas (Druck, prelo). Indicadores qualitativos sugerem que, nos anos 2000, tornou-se mais frequente a flexibilização ou precarização dos vínculos existentes nesse espaço, fenômeno largamente documentado nos estudos sobre terceirização e novos modelos de gestão (a exemplo, Druck; Franco, 2007).

Os indicadores do período também permitem concluir que o empreendedorismo e o trabalho cooperativado continuam sendo minoritários no mercado de trabalho urbano do Brasil e que, tal como ocorre com o "contapropismo", sequer podem ser tomados como uma tendência relevante de reorganização da produção capitalista. Ao que sugerem os indicadores aqui trabalhados, na maior parte dos casos, tais formas de trabalhar continuam acessórias, auxiliares à produção capitalista, quando não apenas espaços de luta pela sobrevivência de desempregados e de segmentos com pouca ou nenhuma chance de acesso a um posto de trabalho assalariado.

Do mesmo modo, a precarização dos vínculos pela via da sua descaracterização (Cooperativas de Trabalho fraudulentas; Contratos de Prestação de Serviço firmados com trabalhadores com registro de pessoa jurídica - P.J, falsos estágios, etc.), embora tenha ganhado relevância no debate sobre a nova configuração da produção capitalista, é bem menos significativa no nível macro, isto é, tais formas de contratação degradam o mercado de trabalho e, juntamente com a ameaça de desemprego, atuam como mecanismo de dominação e de imposição de per- das ao conjunto dos trabalhadores, mas, aparentemente, são bem menos generalizadas do que se imagina, não chegando a ter peso significativo no conjunto da Ocupação. A sua importância parece estar, assim, concentrada em algumas atividades ou setores para os quais são efetivamente essenciais, estando longe de assumir a relevância que tem o vínculo empregatício, formalizado ou não, nos processos produtivos comandados pelo capital.

Tendo em vista essas tendências e na contramão das leituras que propugnaram o "fim dos empregos” (Rifikin, 1995) e a proliferação do empreendedorismo e dos consultores (Sennett, 1999), estariam tais dados indicando que se mantêm a importância e a centralidade da subordinação direta do trabalho ao capital, apesar da acentuada flexibilização dos novos processos produtivos? Sendo essa hipótese verdadeira, sem desprezar a importância das novas formas de contratação do trabalho, nem a recriação de padrões antigos, o estudo dos processos de precarização e flexibilização do trabalho e dos vínculos, assim como o de heterogeneização da classe trabalhadora, deveria voltar-se para o contexto do próprio assalariamento, cada vez mais complexo, mesmo quando considerados os trabalhadores regidos pelo mesmo tipo de contrato.

(Recebido para publicação em novembro de 2010) (Aceito em dezembro de 2010)

\section{REFERÊNCIAS}

ALVES, G; CORSI, F.L. Precarização do trabalho e nova precariedade salarial no Brasil na década de 2000. Da tessitura da redundância à intermitência da contingência salarial. In: GARZA TOLEDO, E.T. de La; NEFFA, J.C. Trabajo y modelos pnoductivos em America Latina: Argentina, Brasil, Colômbia, México y Venezuela luego de la crisis del modo de desarrollo neoliberal. Buenos Aires: CLACSO, 2010. p.231-258.

BORGES, A. Desestruturação do mercado de trabalho e vulnerabilidade social: a Região Metropolitana de Salvador na década de 90. Salvador: Faculdade de Filosofia e Ciências Humanas/ Programa de Pós-Graduação em Ciências Sociais/UFBA, 2003. 374p.

Impactos do desemprego e da precarização sobre famílias metropolitanas. Revista Brasileira de Estudos Populacionais, São Paulo, v.123, n.2, p.205-222, 2006. 
Deficits juvenis ou deficits de lugares? O desemprego e a ocupação dos jovens nos mercados de trabalho do Nordeste e do Sudeste. Revista da ABET, João Pessoa, v.7, p.167-188, 2008a.

Os jovens nos anos 1990: desemprego, inclusão tardia e precariedade. Bahia: Análise \& Dados, Salvador, v.18, n.1, p.157-170, 2008b.

BOURDIEU, P. A precariedade está por toda parte. In: Contrafogos. Rio de Janeiro: Jorge Zahar Editores; 1998. p. 119-127.

O neoliberalismo, utopia (em vias de realização) de uma exploração sem limites. Contrafogos. Rio de Janeiro: Jorge Zahar Editores; 1998b. p. 135-149.

CARDOSO, A. M. Trabalhar, verbo transitivo: destinos profissionais dos deserdados da indústria. Rio de Janeiro: FGV, 2000.

LINHART, D. A desmedida do capital. São Paulo: Boitempo, 2007.

MARQUES, Rosa. R. M. Notas sobre o avanco do neoliberalismo no campo da proteção social. In: III ENCONTRO DE ECONOMIA POLÍTICA, 1998, Niterói, . III Encontro De Economia Política, Anais ... Niterói, v. 2, 1998. p. 1143-1151,

MÉSZAROS, I. Desemprego e precarização. Um grande desafio para a esquerda. In: ANTUNES, Ricardo (Ed.) Riqueza e miséria do trabalho no Brasil. Mundo do trabalho. São Paulo: Boitempo, 2006

POCHMANN, M. O trabalho sob o regime pós-neoliberal no Brasil. In: GARZA TOLEDO, E.T. de La; NEFFA, J.C. Trabajo y modelos productivos em America Latina: Argentina, Brasil, Colômbia, México y Venezuela luego de la crisis del modo de desarrollo neoliberal. Buenos Aires: CLACSO, 2010. p.203-230.

DEDECCA, C.S. O trabalho no Brasil do início do século XXI. Campinas,SP: IE/Unicamp, Relatório Técnico, 2006. $187 \mathrm{p}$

DRUCK, M. G. ; FRANCO, T. Terceirização e precarização: o binômio anti-social em indústrias. In:

(Org.). A perda da razão social do trabalho: terceirização e precarização. São Paulo: Boitempo, 2007.

O avanço da terceirização do trabalho: principais tendências nos últimos 20 anos no Brasil e na Bahia. Bahia: Análise e Dados, Salvador, 2011, n. especial, (prelo).

RIFKIN, J. O fim dos empregos. São Paulo: Makron Books, 1995

SENNETT, R. A corrosão do caráter. São Paulo: Record, 1999.

THEBAUD-MONY, A; DRUCK, G. Terceirização: a erosão dos direitos dos trabalhadores na França e no Brasil. In: Graça Druck, Tânia Franco. (Orgs.). A Perda da Razão Social do Trabalho: Terceirização e Precarização. São Paulo: Boitempo, 2007. p.23-58.

IVO, A.B.L. Viver por um fio: pobreza e política social. São Paulo: Annablume; Salvador: CRH/UFBA, 2008. 
NEW SETTINGS IN URBAN LABOR MARKET IN BRAZIL: notes for discussion

\section{Ângela Borges}

This paper investigates the impact of changes recorded between 2002 and 2009 in the urban labor market in Brazil on the workers, taking into account its segmentation into groups resulting from the intersection of the dimensions of age, sex and education. In it we make a brief analysis of the changes observed in these seven years in the socio-demographic profile of the population of working age to, then, investigate the levels of occupation, unemployment and the formalization of the various segments of workers defined from those variables .To that end, we constructed and analyzed a set of indicators, based on data from the National Survey by Home Sampling (in Portuguese, PNAD), that account for labor market insertion of young men and women, adults and elderly according to education level and the new settings of the labor market that emerge in the expansionary cycle of the economy over the last seven years.

KEYworDs: labor market, age, sex, education, forms of integration.
LES NOUVELLES CONFIGURATIONS DU MARCHÉ DU TRAVAIL URBAIN AU BRÉSIL: annotations pour une discussion

\section{Ângela Borges}

Il s'agit d'une recherche concernant l'impact des variations enregistrées entre 2002 et 2009 sur les travailleurs au sein du marché du travail urbain au Brésil. On tient compte de la segmentation en groupes, résultat de l'intersection des paramètres d'âge, de sexe et de scolarité. On y fait une brève analyse des changements observés, au cours de ces sept années, sur le profil sociodémographique de la population en âge de travailler, pour ensuite étudier les niveaux d'occupation, de non occupation et de formalisation des différents groupes de travailleurs définis à partir de ces variables. À cette fin, nous avons construit et analysé une série d'indicateurs, basés sur les données de la PNAD (Pesquisa Nacional por Amostra de Domicílios/Recherche Nationale par Echantillonnage de Domiciles), qui rendent compte de l'insertion sur le marché du travail d'hommes et de femmes jeunes, d'adultes et de personnes âgées, en fonction de leur niveau de scolarité. Ceci permet de visualiser les nouvelles configurations du marché du travail qui surgissent dans le cycle d'expansion de l'économie au cours de ces sept dernières années.

Mots-CLÉs: marché du travail; âge, sexe, scolarité, formes d'insertion.

Angela $M^{\alpha}$ de Carvalho Borges - Doutora em Ciências Sociais pela Universidade Federal da Bahia. Professora adjunta da Universidade Católica do Salvador, exercendo a função de coordenadora do Mestrado em Políticas Sociais e Cidadania e do Núcleo de Estudos do Trabalho (NET). Pesquisadora Associada ao Centro de Recursos Humanos da UFBA, integrando o Grupo de Pesquisa Trabalho, Trabalhadores e Reprodução Social. Foi membro da Câmara de Assessoramento da FAPESB (Ciências Humanas). Suas pesquisas tratam, especialmente, das seguintes temáticas: estrutura e dinâmica do mercado de trabalho; precarização e vulnerabilidades; trabalho e questão social; pobreza e desigualdades; juventude e trabalho, família e trabalho. Dentre seus trabalhos mais recentes destacamos: Jovens e trabalho: .... In: Neffa, J.C.; Garza Toledo, E. Terra, L. (Orgs.). Trabajo, empleo, calificaciones profesionales, relaciones de trabajo y identidades laborales (Buenos Aires: CLACSO, 2009), p. 217-247, entre outros. 